\section{THE NEW PROFESSOR OF ENGINEERING AT GLASGOW}

$T$ has already been announced in NATURE that 1 the Crown authorities have appointed Prof. James Thomson, C.E., LL.D., to succed the late Prof. IV. J. iI. Rankine in the Glasgow Chair of Enginecring and Mechanics; and as that gentleman has been deemed worthy to occupy the Chair that was long filled by a man of world-wide eminence, it may not be undesirable to give a brief sketch of his professional and scientific career.

Prof. Thomson is the elder brother of Sir IVilliam Thomson, and son of Dr. James Thomson, a former Professor of Mathematics in the University of Glasgow: The early part of his education was obtained in the Royal Belfast Academical Institution, and he completed his studies in Glasgow, where he obtained the degree of M.A. in 1840 , with honourable distinction in Mathematics and Natural Philosophy. During the year $18+1-42$, he was a student in the class of Civil Engineering and Mechanics under Prof. Lewis D. B. Gordon, C.E., Rankine's predccessor, and even then he was distinguished for his accurate mathematical and physical knowledge, and for his ready appreciation of the principles of applicd mechanics. Heafterwardsbecame an industrious pupil in the Horscley Iron Works and Manufactory, near Tipton, in South Staffordshire, and subsequently he entered the service of Mr. (now Sir) IVilliam Fairbairn, in whose workshops on the Isle of Dogs and in Manchester he had the benefit of assisting to execute engineering works of the greatest magnitude, and of great variety. After prosecuting his profession for several years in England and Scotland, he ultimately settled down in Belfast as a civil engineer.

When the Professorship of Civil Enginecring in Queen's College, Belfast, became vacant in the year 1857, Mr. Thomson obtained the appointment. He has now occupied that position for a period of fifteen years.

Besides attending to the duties of his class, Prof. Thomson carried on an extensive practice as a consulting engineer, both at home and abroad, chiefly in connection with water supply, irrigation, the drainage of sugar plantations in Demerara and Jamaica, and other swampy lands, and in designing machinery for the same, and in other hydraulic works. One of his carliest inventions was the well-known Vortex Turbine, which affords an admirable example of an unusual combination of great scientific knowledge and practical skill in the same person. This application of mechanical principles is one of the most successful means of turning water power to advantage that has hitherto been placed at the service of the engineering profession. Many examples of the Vortex Wheel are now in successful operation in various parts of the world, and the invention was deemed to be so important that the Privy Council renewed the patent when the ordinary period of fourteen years had expired. Another of his useful inventions is the Jet Pump and Intermittent Reservoir for the drainage of swampy lands.

Among Prof. Thomson's inquiries in the domain of pure physics a prominent place must be given to those which he instituted regarding the lowering of the freezing temperature of water hy pressure. This he determined by theoretical considerations entirely, and the result announced by Prof. James Thomson was afterwards exactly confirmed by the experiments instituted by his distinguished brother. The "arrival by theory without the aid of experiment at so extraordinary a physical fact, calls to my mind most forcibly," says Joule, "the discovery of Neptune by Adams and Leverrier, and is one great step towards the position to which we may eventually hope science to attain, when a perfect acquaintance with theoretical principles will enable us to dispense with the appeal to experiment so necessary, in most cases, at the present time." This discovery and its experimental verification immediately suggested a perfect solution of the problem of the descent of glacicrs, and it has since led to many kindred discoveries in pure science. Like his predecessor, Prof. Thomson has extensively contributed to the advancement of science through the medium of the British Association. On five scparate occasions he has been sclected as the Secretary of the Mechanical Section of that body, and he has been a number of times specially deputed to make reports and conduct experimental researches for the solution of questions in practical engineering. The tendency of Prof. Thomson's mind may be, to some extent, judged of by the character of the papers on physical, mathematical, and mechanical subjects which he has published or commu. nicated to various scientific bodies. They are nearly forty in number, and are published in full or abstract in the Cambridge and Dublin Mathematical Fournal, the Ediuburgh New Philosophical Fournal, the Transactions of the Royal Societies of London and Edinburgh, the Proceed. ings of the British Association, and the Transactions of the Institution of Engincers in Scotland.

Prof. Thomson's honorary degrec of LL.D. was obtained from the University of Glasgow about two years ago. His formal induction by the Senatus of the University took place last month, and his professional duties in his alma mater will commence in the ensuing winter session. JOHN MAYER

\section{THE FERTILISATION OF THE IVILD PANSY}

$A$ MONG the accurate and acute observations of $C$. $C$. A Sprengel towards the close of last century, * which have received but scant attention from his successors, even down to our own day, was one on the subject of the colouring of variegated flowers. This botanist, with an insight into the mutual relationships of animal and vegetable life far in advance of his age, suggests that this colouring may serve as a guide to insects in seeking for the honey which serves for their food, and the search for which is so powerful an agent in the conveyance of the pollen, and the consequent fertilisation of the flower. Sprengel pointed out that in almost all variegated flowers the variegation follows a regular pattern, and that when it consists of streaks or stripes, these streaks almost invariably point to the nectary, or the receptacle of the sweet secretions which form the food of insects, in whatever part of the flower it may be situated. With this idea as a starting point, an interesting line of inquiry may be carried out as to the connection between the presence of scent and the absence of variegation in flowers. It will be found as a general rule, though not without exceptions -and it would be very interesting to attempt to trace the reason of these exceptions-that those flowers which possess a powerful odour are (in the native state) self- or whole-coloured, while brilliantly variegated flowers arc, as a rule, scentless. On the hypothesis that cach of these properties has for its object the attraction to the flower of the insect necessary for the fertilisation of its seeds, it is easy to be seen that the presence of both in the same flower is needless; and hence we find that Nature is in the habit of husbanding her resources, and not supplying needlessly to the same flower two different provisions for securing the same end.

Having had an opportunity during the present spring of observing the structure, with reference to the phenomena of fertilisation, of the flower of the common Wild Pansy (Viola tricolor sub-sp. arveinsis of Hooker's "Student's Flora") I have thought a description of it might be of interest to the readers of NATURE, and especially to anyone who is able to contrast the phenomena in the variegated and scentless pansy with those in the scented and almost whole-coloured sweet violet.

The corolla of the wild pansy consists of five petals

* Das entdeckte Gehcimniss der Natur im Bau und in der Eefruchtung der Dlumen: von Christian Konrad Sprengel. Ecrlin, 1793. 